\title{
III WORKSHOP DA ENGENHARIA DE ALIMENTOS
}

III Food Engineering Workshop

III Taller de Ingeniería de Alimentos

Adriana Régia Marques de Souza ${ }^{1}$

Editorial

${ }^{1}$ Docente do Curso de Engenharia de Alimentos, da Universidade Federal de Goiás, Goiânia, Brasil

*Correspondência: Escola de Agronomia, Avenida esperança, s/n. Campus Samambaia, Goiânia, Goiás, Brasil. CEP: 74.690-900.e-mail adriana_regia_souza@ufg.br

A ideia da realização do Workshop da Engenharia de Alimentos nasceu da vontade dos estudantes e docentes do curso de Engenharia de Alimentos, da Universidade Federal de Goiás, de atualização, além de resgatar a importância de eventos organizados por alunos e em suas edições anteriores, 2016 e 2017, o evento contou com a participação de 250 pessoas. Sempre com caráter integrador, a organização do evento é realizada pelos grupos que compõe o curso: Associação Atlética Acadêmica Engenharia de Alimentos (A.A.A.E.A.), Centro Acadêmico do curso de Engenharia de Alimentos (CAENA), Consultoria Integrada de Produção e Processamento de Alimentos - Consultoria Júnior (CIPPAL), Grupo de Estudos Avançados do Leite e dos seus Derivados (GELAC), Grupo de Estudos de Alimentos Orgânicos (GEPOA), Programa de Educação Tutorial de Engenharia de Alimentos (PET EngAli) e Projeto de Extensão Cervejamos.

O III Workshop da Engenharia de Alimentos, aconteceu entre 22 e 24 de agosto de 2018, na Escola de Agronomia, da Universidade Federal de Goiás, em Goiânia (GO) e teve como tema central: Gestão e Inovação. O evento foi direcionado para estudantes de graduação e profissionais das áreas de Ciência, Tecnologia e Engenharia de Alimentos, Nutrição, Ciência Agrárias e áreas afins. Seu objetivo foi promover, por meio de palestras, minicursos e apresentação de trabalhos, uma maior interação entre os estudantes, professores e profissionais ligados à produção de alimentos, além da troca de experiências e conhecimentos entre os participantes, expondo temas atuais das áreas de ciência e tecnologia de alimentos, formação pessoal e empresarial.

Estudantes de graduação, de diferentes Universidades e Estados, proporcionaram uma real integração e discussão dos temas trabalhados. Ao todo foram 150 pessoas envolvidas no evento, que contou com palestrantes de diferentes Instituições de Ensino e profissionais de várias indústrias da área de alimentos. Além de palestras, também foram realizados cursos práticos, apresentação de trabalhos científicos e visitas técnicas a diferentes empresas com o intuito de 
trazer a vivência do Engenheiro de alimentos aos congressistas.

Foram apresentados 15 trabalhos científicos com temas variados e de relevância para a área de ciência, tecnologia e engenharia de alimentos. Divulgar as pesquisas realizadas nas Universidades é muito importante para impulsionar a inovação e a resolução de problemas enfrentados pela sociedade. 